\title{
Pengembangan Panduan Teknik Flooding dalam Konseling Behavioral untuk Mereduksi Fear of Missing Out Siswa Sekolah Menengah Atas
}

\author{
(Developing Guidance on Flooding Techniques in Behavioral Counseling to Reduce \\ High School Students' Fear of Missing Out) \\ Ovita Dewi Sandra Wati*, Yuliati Hotifah, M. Ramli \\ ${ }^{1}$ Universitas Negeri Malang, Jl. Semarang No. 5 Malang, Jawa Timur, Indonesia \\ *Penulis korespondensi, Surel: ovita.dewi.1701116@students.um.ac.id
}

Paper received: 24-Nov-2021; revised: 20-Dec-2021; accepted: 24-Dec-2021

\begin{abstract}
Research and development in this study aim to produce a product of Flooding technique guidance in Behavior Counseling to reduce Fear of Missing Out of high school students who are theoretically and practically acceptable. The design of this study uses research and development steps: preliminary studies, product development, and product testing. The guide was tested using a Likert scale and concluded with the Aiken rater agreement analysis. The test results show that the Flooding technique guide has been theoretically and practically acceptable to reduce high school students' Fear of Missing Out.
\end{abstract}

Keywords: flooding technique; fear of missing out; research and development

\begin{abstract}
Abstrak
Penelitian dan pengembangan pada penelitian ini bertujuan menghasilkan produk panduan teknik Flooding dalam konseling Behavioral untuk mereduksi Fear of Missing Out siswa SMA yang berterima secara teoritis maupun praktis. Rancangan penelitian ini menggunakan Langkah penelitian dan pengembangan: studi pendahuluan, pengembangan produk dan uji produk. panduan diuji menggunakan skala Likert dan disimpulkan dengan analisis kesepakatan rater Aiken. Hasil uji menunjukkan bahwa panduan teknik Flooding telah berterima secara teoritis maupun praktis untuk mereduksi Fear of Missing Out siswa SMA.
\end{abstract}

Kata kunci: teknik flooding; fear of missing out; penelitian dan pengembangan

\section{Pendahuluan}

Sosial media telah mengubah cara berkomunikasi manusia, dari awal yang sederhana sebagai platform untuk berbagi foto, mendiskusikan kepentingan bersama, dan melengkapi interaksi sosial, hingga menjadi sumber perubahan di berbagai bidang (Abdelraheem \& Ahmed, 2018). Saat ini, timbull gejala baru gangguan penggunaan internet yang memiliki ciri kecanduan sosial media dan takut ketinggalan aktivitas orang lain diiringi dengan kecemasan berlebih jika tidak membuka sosial media yang disebut dengan Fear of Missing Out (FoMO). Kecemasan adalah suatu perasaan subjektif perihal ketegangan mental yang menyebabkan kegelisahan sebagai reaksi dari ketidakmampuan individu dalam mengatasi suatu permasalahan atau ketiadaan rasa aman, perasaan tersebut disertai dengan perubahan pada fisiologis dan psikologis individu.

Kecemasan merupakan suatu perasaan khawatir dan takut yang tidak dapat diprediksi dengan jelas sebabnya, kecemasan memiliki kekuatan besar dalam pengendalian tingkah laku, 
seperti tingkah laku malasuai atau menyimpang menurut. Fear of Missing Out adalah sindrom kecemasan sosial yang ditandai dengan hasrat untuk terus terhubung dengan apa yang orang lain lakukan (Przybylski, Murayama, DeHaan, \& Gladwell, 2013). Gejala Psikopatologi yang menandai individu terkena FoMO adalah stress, cemas, merasa kesepian dan harga diri yang rendah. FoMO merupakan jenis kecemasan eksistensial dimana individu tidak dapat melepaskan diri dari sosial media. Faktor utama yang mendasari FoMO adalah tidak terpenuhi kebutuhan untuk berinteraksi atau terhubung dengan orang lain atau kedekatan dengan orang lain (Relatedness) dan tidak terpenuhi kebutuhan akan aktualisasi diri (self). Dampak dari FoMO yaitu merasa kehilangan, stress, cemas dan merasa jauh jika tidak mengetahui atau ketinggalan perkembangan peristiwa di sosial media. Jejaring sosial mampu menimbulkan sifat adiktif pada seseorang dan cenderung merasa ketagihan untuk terus mengoperasikannya, sehingga melupakan kegiatan wajib yang harus dilakukan di dunia nyata.

Fakta menunjukkan bahwa 87,5\% siswa menggunakan smartphone untuk terhubung ke internet dan sosial media dan rata-rata mereka memiliki minimal satu akun sosial media (Tunc-Aksan \& Akbay, 2019). Fear of Missing Out juga ditemukan di SMA Laboratorium UM Malang. Data menunjukkan bahwa 3,01\% siswa memiliki tingkat Fear of Missing Out yang sangat tinggi, 45,78\% terkategori tinggi, dan 51,20\% terkategori rendah (Gambar 1).

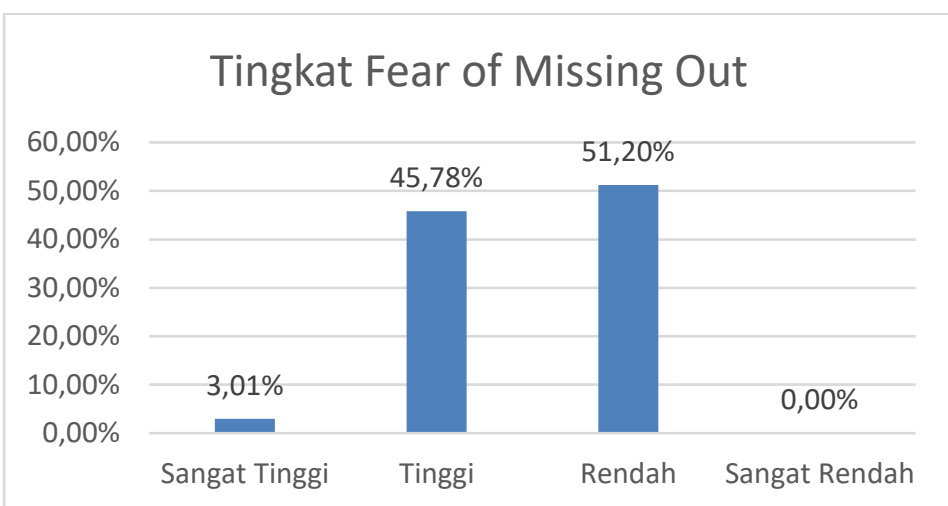

Gambar 1. Tingkat Fear of Missing Out siswa SMA Laboratorium UM

Melihat dari data tingkat FoMO di lapangan, maka perlu siswa perlu segera dibantu mengatasi FoMO. Beberapa solusi yang pernah digunakan untuk membantu mereduksi FoMO adalah teknik modifikasi. Salah satu bentuk solusi tersebut teknik Vipassana (Adriansyah, Saputri, Lawolo, \& Arsha, 2018). Teknik Vipassana yaitu pelatihan meditasi untuk pencabutan kekotoran mental dan menghasilkan kebahagiaan tertinggi akan kebebasan penuh. Beberapa solusi yang pernah digunakan, teknik dirasa asing dalam ranah konseling, tidak semua aspek kecemasan, ketakutan dan kekhawatiran tersentuh melalui teknik yang diberikan.

Perilaku kecanduan disertai kecemasan cenderung mengganggu aktivitas pembelajaran dan nilai akademik rendah, ketakutan siswa kehilangan momen akan semakin meningkat diiringi kecanduan sosial media, dengan menurunnya kompetensi sosial dan akademik siswa, kecanduan siswa terhadap sosial media juga meningkat (Tunc-Aksan \& Akbay, 2019) Fear of Missing Out juga dapat menimbulkan kurangnya interaksi sosial antara siswa dan lingkungannya. Mengacu pada Standar Kompetensi Peserta Didik (SKKPD) SMA, Konselor bertanggung jawab mendorong peserta didik/konseli untuk mewujudkan perilaku dan kompetensi sesuai dengan tugas perkembangan dalam tindakan nyata sehari-hari. Hal tersebut didasarkan pada SKKPD pada aspek kesadaran tanggung jawab sosial, yaitu siswa 
dituntut menyadari nilai-nilai persahabatan dan keharmonisan dalam konteks keragaman interaksi sosial dan berinteraksi dengan orang lain atas dasar kesamaan. Oleh karena itu, guru BK/ konselor sekolah perlu memberikan intervensi kepada konseli dengan cara menumbuhkan kesadaran sosial agar dapat membantu konseli dalam memenuhi kompetensi SKKPD aspek kesadaran tanggung jawab

Teknik Flooding merupakan teknik yang bertujuan menurunkan tingkat kecemasan individu dengan cara membanjiri individu menggunakan keadaan atau situasi penyebab kecemasan dan tingkah laku yang tidak diharapkan terjadi, sampai individu sadar bahwa yang selama ini dicemaskan atau ditakuti tidak terjadi. Teknik tersebut diprediksi mampu menurunkan FoMO. Teknik pembanjiran dilandasi paradigma mengenai penghapusan pengalaman. Teknik flooding memunculkan stimulus yang terkondisi secara berulang-ulang tanpa disertai pemberian reinforcement. Pada teknikflooding, dimunculkan stimulus penyebab kecemasan kemudian konseli membayangkan atau dihadapkan oleh situasi cemas, dan konselor berusaha mempertahankan kecemasan konseli hingga kecemasan itu menurun.

Tujuan penelitian ini untuk menghasilkan buku panduan teknik Flooding untuk mereduksi Fear of Missing Out siswa SMA yang berterima secara teoritis maupun praktis. Buku panduan digunakan oleh konselor sebagai petunjuk teknis pelaksanaan teknik Flooding. Sejauh ini Flooding efektif untuk mereduksi kecemasan, baik kecemasan sosial, kecemasan menghadapi ujian. Teknik Flooding yang efektif akan memudahkan konselor dalam memberi layanan konseling sesuai teknik yang digunakan.

\section{Metode}

Rancangan penelitian ini menggunakan model research and development Borg \& Gall yang telah dimodifikasi (Sukmadinata, 2012). Langkah pengembangan dilakukan dengan tiga tahapan, yaitu: (1) Studi pendahuluan, (2) pengembangan produk dan (3) uji produk. pada tahap studi pendahuluan terdapat 3 langkah kegiatan yaitu (1) need assessment, (2) studi kepustakaan dan (3) kuesioner pengukuran. Need assessment bertujuan untuk mengumpulkan data yang berkaitan dengan Fear of Missing Out siswa yang dilakukan dengan wawancara, angket kebutuhan konseling flooding dan observasi. Studi kepustakaan dilakukan dengan mencari referensi konsep atau teori yang dikembangkan yakni terkait Flooding dan FoMO. Kuesioner pengukuran dilakukan dengan melakukan pelancaran angket kepada siswa, angket dimodifikasi dan dikembangkan oleh peneliti. Berdasarkan hasil need assesment dan studi lapangan secara konseptual dan praktis didukung oleh penelitian sebelumnya, menunjukkan bahwa teknik flooding lebih efektif jika dilaksanakan secara tatap muka karena berkaitan dengan pembanjiran kecemasan. Berdasarkan hasil tersebut, draft model atau produk awal yang akan dikembangkan adalah buku panduan teknikflooding.

Tahap pengembangan produk terdiri dari beberapa langkah yaitu: (1) merumuskan atau menentukan tujuan, (2) penyusunan prototype produk. Pada langkah pertama yaitu merumuskan atau menentukan tujuan diadakannya panduan teknik flooding. Pada tahap penyusunan prototype produk terdapat beberapa bagian yang menjadi isi dari panduan yaitu menyusun petunjuk penggunaan panduan, pendahuluan, prosedur pelaksanaan konseling teknikflooding dalam konseling behavior. Selain pengembangan produk panduan, peneliti juga menyusun instrumen evaluasi konseling, instrumen kelayakan materi dan media untuk mengetahui tingkat kelayakan produk. 
Tahap uji produk, langkah yang ditempuh yaitu uji ahli media, uji ahli materi dan uji calon pengguna. Penilaian dilakukan oleh 7 orang ahli yakni 2 orang ahli materi, 2 orang ahli media dan 3 orang calon pengguna produk. Uji ahli dilaksanakan untuk mengetahui keberterimaan produk dari aspek kejelasan, kegunaan, kemudahan dan kemenarikan. Pertama peneliti melaksanakan uji ahli media dan melaksanakan revisi produk, setelah revisi dilanjutkan dengan pelaksanaan uji materi konseling dan melaksanakan revisi kembali, setelah revisi materi selesai dilanjutkan dengan uji calon pengguna produk yaitu guru BK atau konselor sekolah. Hasil dari uji calon pengguna menunjukkan data bahwa panduan konseling teknik flooding layak dan berterima dari segi kejelasan, kegunaan, kemudahan dan kemenarikan.

Jenis data yang digunakan dalam penelitian ini adalah data berupa angka dan non angka. Data angka yang merupakan data kuantitatif adalah hasil penilaian terhadap produk panduan konseling dalam bentuk angka, yang diperoleh dari format penilaian uji ahli. Data non angka yang merupakan data kualitatif merupakan data yang diperoleh dari kritik, saran atau masukan secara umum tentang pengembangan panduan konseling dari uji ahli dan uji kelompok kecil. Instrumen penelitian ini ada 2 yaitu: (1) instrumen pengumpulan data berupa kuesioner angket, dan (2) instrumen penilaian dalam bentuk format penilaian untuk mengetahui kelayakan produk. Teknik analisis data yang digunakan untuk mengukur kelayakan produk adalah analisis kesepakatan rater yang diusulkan oleh Aiken (1985) dengan menggunakan rumus sebagai berikut:

$$
V=\sum_{I=1}^{C-1} \frac{i n_{i}}{N(c-1)}
$$

\section{Keterangan:}

$\mathrm{V} \quad=$ indeks kesepakatan rater

$s \quad=$ skor yang dipilih rater - skor terendah dalam instrument

$n \quad=$ jumlah rater

c = banyak kategori yang dapat dipilih rater

Hasil analisis kesepakatan rater usulan Aiken memberikan hasil berupa indeks koefisien rater dalam rater angka 0,00-1,00 dengan interpretasi hasil analisa merujuk pada tabel 1.

Tabel 1. Kategori Indeks Kesepakatan Rater usulan Aiken

\begin{tabular}{cc}
\hline Indeks Kesepakatan Rater & Kategori Validitas \\
\hline $0,81-1,00$ & Tinggi \\
$0,41-0,80$ & Sedang \\
$0,00-0,40$ & Rendah \\
\hline
\end{tabular}

Data verbal utama hasil penilaian dan evaluasi hasil dan calon pengguna dalam bentuk saran, komentar, dan kritik. Data verbal hasil penilaian ahli dan calon pengguna juga didukung melalui data sekunder. Data verbal tersebut selanjutnya dilakukan analisis deskriptifinterpretatif oleh peneliti. 


\section{Hasil dan Pembahasan}

\subsection{Hasil}

Penelitian dan pengembangan ini menghasilkan produk berupa buku panduan teknik Flooding untuk mereduksi Fear of Missing Out bagi guru bimbingan konseling/konselor sekolah yang telah melalui tahap pengkajian format dan isi panduan. Pengkajian format terkait dengan penyusunan desain, tata letak penyajian dan pemilihan bahan panduan. Pengadaan produk panduan konseling menggunakan bahan-bahan yang telah dipertimbangkan dari sisi estetika, daya tahan bahan dan harga. Ukuran panduan yang telah dipertimbangkan adalah ukuran B5 (182mm x $257 \mathrm{~mm})$. pemilihan bahan untuk membuat sampul panduan adalah menggunakan kertas art paper Glossy 260 gram. Halaman isi menggunakan kertas HVS yang sesuai dengan kebutuhan isi panduan yang tidak begitu memuat banyak gambar berwarna.

Berdasarkan hasil perhitungan kuesioner fear of missing out dengan teknik korelasi product moment nilai rtabel $=0,512$ dengan program SPSS 26.0. Dari hasil perhitungan korelasi product moment dapat diketahui bahwa skor pada masing - masing pernyataan berkorelasi secara signifikan dengan total skor, ditunjukkan dengan $r$ hitung lebih besar dari $r$ tabel. Sehingga dapat disimpulkan bahwa seluruh item pernyataan valid sehingga bisa digunakan sebagai alat pengumpulan data Fear of Missing Out. Berdasarkan uji reliabilitas diketahui bahwa nilai Alpha-Cronbach untuk semua variabel lebih besar dari 0,6 yakni alpha Cronbach 0,944. Dengan demikian semua butir kuesioner dinyatakan reliabel sehingga dinyatakan baik dan layak dipergunakan sebagai alat pengumpul data Fear of Missing Out.

Berdasarkan hasil perhitungan penilaian ahli materi BK yang mencakup ketepatan, kegunaan, kemudahan dan kemenarikan memberikan indeks rata-rata pada aspek ketepatan sebesar 0,81, aspek kegunaan sebesar 0,94, aspek kemudahan sebesar 0,75, aspek kemenarikan 0,95 dengan demikian ahli materi BK menyatakan bahwa panduan teknik Flooding termasuk kedalam kategori layak digunakan sebagai panduan. Selain data angka, penilaian ahli materi menghasilkan data verbal/non angka dalam bentuk saran terkait panduan yang dikembangkan yaitu: (1) beberapa layout perlu dirapikan sedikit, (2) petunjuk khusus yang point 3 tidak perlu dicantumkan karena topik netral memang menjadi bagian yang umum digunakan dalam konseling, (3) Bagian prasyarat jika latar belakang S1 BK maka juga disebutkan guru BK.

Penilaian ahli media pembelajaran memberikan indeks validitas ahli dari aspek ketepatan sebesar 0,95, aspek kegunaan sebesar 1,00, aspek kemudahan 0,87 dan aspek kemenarikan 0,87 dengan demikian ahli media pembelajaran menyatakan bahwa buku panduan termasuk kedalam kategori layak digunakan. Data verbal/non angka dalam bentuk saran terkait panduan yang dikembangkan yaitu: (1) font lebih baik menggunakan Times New Roman, (2) Background cover diganti warna agar tidak overlapping dengan logo (Gambar 2, Gambar 3, Gambar 4 dan Gambar 5).

Uji calon pengguna dilakukan kepada 3 orang guru BK, hasil uji menunjukkan dari aspek ketepatan memberikan rata-rata indeks validitas ahli sebesar 0,85 , aspek kegunaan 0,87 , aspek kemudahan 0,93 dan aspek kemenarikan 0,92 sehingga dapat disimpulkan bahwa panduan layak digunakan dan memenuhi aspek keberterimaan produk. data verbal/non angka yaitu: (1) daftar rujukan dicantumkan semua. 


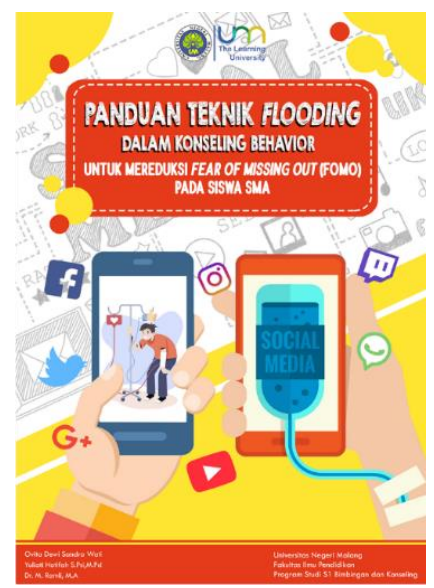

Gambar 2. Cover Depan Buku Panduan Teknik Flooding dalam Konseling Behavior untuk Mereduksi Fear of Missing Out Siswa SMA

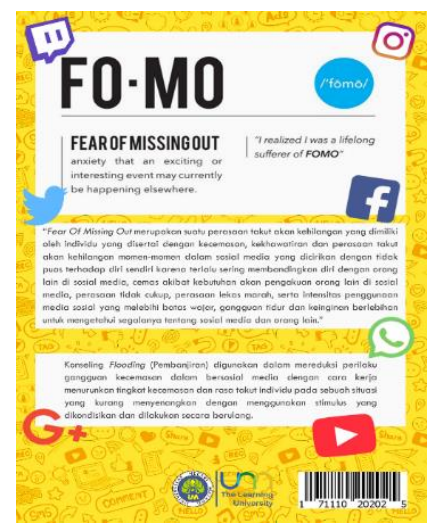

Gambar 3. Cover Belakang Buku Panduan Teknik Flooding Dalam Konseling Behavior untuk Mereduksi Fear of Missing Out Siswa SMA

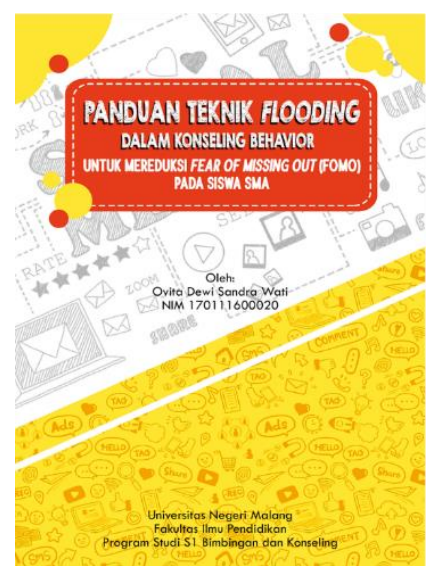

Gambar 4. Cover dalam Buku Panduan Teknik Flooding dalam Konseling Behavior untuk mereduksi Fear of Missing Out Siswa SMA 


\subsection{Pembahasan}

Produk panduan teknik flooding dalam konseling behavior secara fisik telah memenuhi kriteria ketentuan yang ada. Buku panduan memiliki standar tampilan serta isi produk yang sesuai dengan ketentuan. Ukuran buku panduan yang dihasilkan yakni ukuran B5 dan akan dibuat pula dalam bentuk soft file. Bentuk soft file, bertujuan agar memudahkan dalam pemanfaatannya (Çelikbaş, 2011; Giles III, 2001). Buku panduan memiliki desain menarik yang dilengkapi dengan gambar ilustrasi sehingga membentuk warna yang beragam dengan background logo sosial media sesuai dengan topik Fear of Missing Out.

Pendahuluan seharusnya berisi rasional penulisan (Jawaid \& Jawaid, 2019). Pada panduan teknik Flooding dalam konseling behavior, pendahuluan menjabarkan tentang rasional dibuatnya panduan berdasarkan hasil angket kebutuhan konseling dan dikuatkan dengan beberapa jurnal penelitian terkait urgensi reduksi kecemasan dan dampak Fear of Missing Out bagi siswa yang dilengkapi dengan tujuan penelitian pengembangan dan sasaran pengguna panduan yaitu guru BK SMA Laboratorium UM. Pada bab II dipaparkan wawasan konsep yang menjabarkan secara rinci mengenai Fear of Missing Out menurut para ahli, aspekaspek Fear of Missing Out dan faktor yang memengaruhi terjadinya Fear of Missing Out. Kemudian dijelaskan tentang teknik Flooding dalam konseling behavior dan prosedur pelaksanaan teknik Flooding untuk mereduksi Fear of Missing Out siswa.

Panduan haruslah berisi petunjuk singkat dan lengkap agar dapat digunakan dengan mudah (Wellhausen \& Fiesser, 2011). Pada panduan teknik flooding, juga disertakan Rencana Pelaksanaan Layanan (RPL) Konseling yang digunakan sebagai acuan konselor dalam pemberian layanan yang berkaitan dengan Fear of Missing Out khususnya teknik Flooding mulai dari tahap persiapan konseling, konseling sesi 1, konseling sesi 2, konseling sesi 3, konseling sesi 4 dan pasca konseling. Pada bab 4 dilampirkan beberapa format penilaian yakni instrument Fear of Missing Out, format observasi, evaluasi pelaksanaan konseling. Panduan teknik Flooding dalam konseling Behavioral untuk mereduksi Fear of Missing Out siswa SMA memiliki keunggulan yang pertama adalah praktis, lengkap karena produk panduan ini memaparkan materi pengertian Fear of Missing Out, aspek dan faktor penyebabnya. Panduan ini juga memaparkan materi mengenai konseling Flooding dan prosedurnya dalam mereduksi Fear of Missing Out sehingga memudahkan konselor dalam melakukan layanan konseling Flooding. 
Keunggulan selanjutnya terdapat pada biaya produksi. Biaya produksi pembuatan panduan konseling Flooding ini sangat murah, hal ini dikarenakan bahan yang dibutuhkan adalah kertas glossy yang banyak diperjual belikan di percetakan dan toko kertas. Tampilan produk yang menarik dapat membuat orang tertarik (Tiwasing, Sahachaisaeree, \& Hapeshi, 2014), demikian pula dengan produk panduan yang dikembangkan. Produk juga memiliki keunggulan dalam desain, dengan mengusung tema sosial media pada bagian cover diharapkan konselor memiliki ketertarikan untuk membaca dan memahami isi dalam panduan. Dari desain media yang mengusung tema sosial media peneliti tidak serta merta asal memilih tema, pemilihan tema didasarkan pada nilai Fear of Missing Out yang identik dengan sosial media

Pandemi Covid-19 mengharuskan pembatasan kegiatan di luar rumah (Aji, 2020). Hal ini juga berdampak pada proses pengembangan panduan teknik Flooding dalam konseling behavioral. Dampak tersebut adalah panduan ini belum bisa dilaksanakan di uji cobakan kepada subjek penelitian.

\section{Simpulan}

Produk panduan teknik Flooding dalam konseling behavioral untuk mereduksi Fear of Missing Out bagi siswa SMA memenuhi unsur keberterimaan secara teoritis maupun praktis yakni dari aspek ketepatan, kegunaan, kemudahan dan kemenarikan seluruh isi panduan. Keberterimaan format ini menandakan bahwa panduan tersebut telah diterima dan dapat digunakan sebagai media bagi konselor atau guru BK di sekolah untuk melaksanakan layanan konseling.

\section{Daftar Rujukan}

Abdelraheem, A. Y., \& Ahmed, A. M. (2018). The impact of using Mobile Social Network Applications on Students' Social-Life. International Journal of Instruction, 11(2), 1-14. https://doi.org/10.12973/iji.2018.1121a

Adriansyah, M. A., Saputri, A., Lawolo, A. N., \& Arsha, J. S. (2018). Vipassana Sebagai Upaya Preventif Bagi Penderita Fear Of Missing Out (FoMo). Psikostudia: Jurnal Psikologi, 7(1), 50-59.

Aiken, L. R. (1985). Three coefficients for analyzing the reliability and validity of ratings. Educational and Psychological Measurement, 45(1), 131-142.

Aji, R. H. S. (2020). Dampak Covid-19 pada Pendidikan di Indonesia: Sekolah, Keterampilan, dan Proses Pembelajaran. SALAM: Jurnal Sosial Dan Budaya Syar-I, 7(5), 395-402. https://doi.org/10.15408/sjsbs.v7i5.15314

Çelikbaș, Z. (2011). EPUB use in digital libraries: Developing an online epub creator application. Digital Publishing and Mobile Technologies, 15th International Conference on Electronic Publishing, 120.

Giles III, J. (2001). Digital files easier to handle but at what price? Quick Printing, 24(7), 20-22.

Jawaid, S., \& Jawaid, M. (2019). How to write introduction and discussion. Saudi Journal of Anaesthesia, 13(5), 18. https://doi.org/10.4103/sja.SJA_584_18

Przybylski, A. K., Murayama, K., DeHaan, C. R., \& Gladwell, V. (2013). Motivational, emotional, and behavioral correlates of fear of missing out. Computers in Human Behavior, 29(4), 1841-1848.

Sukmadinata, N. S. (2012). Metode Penelitian. In Bandung: PT Remaja Rosda Karya.

Tiwasing, W., Sahachaisaeree, N., \& Hapeshi, K. (2014). Design goals and attention differentiations among target groups: A case of toy packaging design attracting children and parents' purchasing decision. Design Principles and Practices, 7(1), 29-43.

Tunc-Aksan, A., \& Akbay, S. E. (2019). Smartphone Addiction, Fear of Missing Out, and Perceived Competence as Predictors of Social Media Addiction of Adolescents. European Journal of Educational Research, 8(2), 559-566. 
Buletin Konseling Inovatif, 1(2), 2021, 55-63

Wellhausen, T., \& Fiesser, A. (2011). How to write a pattern? Proceedings of the 16th European Conference on Pattern Languages of Programs - EuroPLoP '11, 1-9. New York, New York, USA: ACM Press. https://doi.org/10.1145/2396716.2396721 